\title{
In Situ Green Synthesis of Mil-100(Fe) Modified Edta as an Enhanced Candidate Detoxifying Agent of Lead Heavy Metal (Pb) and Its Adsorption Characteristics
}

\section{Witri Wahyu Lestari ( $\nabla$ witri@mipa.uns.ac.id)}

Universitas Sebelas Maret Fakultas Matematika dan Ilmu Pengetahuan Alam https://orcid.org/00000003-1005-5374

\section{Rika Meilani}

Universitas Sebelas Maret Fakultas Matematika dan Ilmu Pengetahuan Alam

\section{If Nurcahyo}

Universitas Sebelas Maret Fakultas Matematika dan Ilmu Pengetahuan Alam

\section{Larasati Larasati}

Universitas Sebelas Maret Fakultas Matematika dan Ilmu Pengetahuan Alam

\section{Research Article}

Keywords: adsorption, detoxification, EDTA, isotherm, kinetic, MIL-100(Fe), Pb2+

Posted Date: September 13th, 2021

DOI: https://doi.org/10.21203/rs.3.rs-810297/v1

License: (c) (i) This work is licensed under a Creative Commons Attribution 4.0 International License.

Read Full License 


\title{
IN SITU GREEN SYNTHESIS OF MIL-100(Fe) MODIFIED EDTA AS AN ENHANCED CANDIDATE DETOXIFYING AGENT OF LEAD HEAVY METAL (Pb) AND ITS ADSORPTION CHARACTERISTICS
} (

\author{
Witri Wahyu Lestari, Rika Meilani, If Nurcahyo, Larasati Larasati \\ Department of Chemistry, Faculty of Mathematics and Natural Sciences, Universitas Sebelas Maret, Jl. Ir. \\ Sutami No. 36 A Kentingan, Jebres, Surakarta, 57126, Indonesia \\ Corresponding author: witri@mipa.uns.ac.id
}
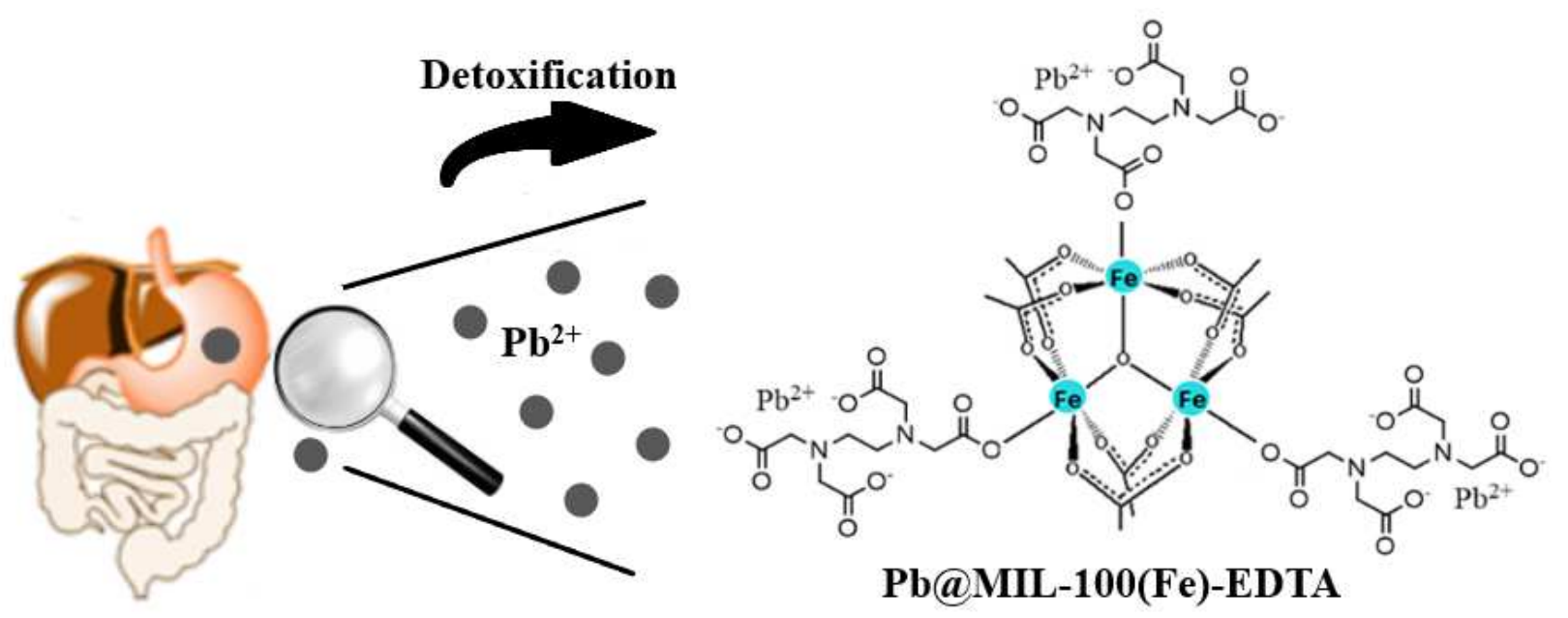

12 Abstract:

EDTA-modified MIL-100(Fe) (MIL = Matériaux de 1'Institut Lavoisier) was successfully

14 prepared in situ using an electrochemical method. The porous nature of the material and its high

15 stability under intestinal and stomach conditions present it as a great candidate agent for lead

16 detoxification. Kinetic and isotherm investigations revealed that the adsorption of $\mathrm{Pb}^{2+}$ ions in

17 MIL-100(Fe)-EDTA followed a pseudo-second order kinetic model with a rate constant of 0.0109

$18 \mathrm{~g} / \mathrm{mg}$.min and a Langmuir isotherm model with an adsorption energy of $31.29 \mathrm{~kJ} / \mathrm{mol}$. The

19 synthesized MIL-100-EDTA showed three times enhanced performance than MIL-100(Fe) in $\mathrm{Pb}^{2+}$

20 adsorption study. Optimum adsorption was achieved at $\mathrm{pH} 3$ at an initial concentration of 5 ppm

21 and a contact time of $12 \mathrm{~h}$, yielding adsorption efficiency and capacity of up to $86.65 \%$ and 3.68

$22 \mathrm{mg} / \mathrm{g}$, respectively.

23 Keywords: adsorption, detoxification, EDTA, isotherm, kinetic, MIL-100(Fe), $\mathrm{Pb}^{2+}$ 


\section{Introduction}

The increasing use of lead in various products, including dye, paint, ceramics, glasses, jewelries, and toy industries, gives rise to the high exposure of the environment and humans to heavy metals. The World Health Organization categorized lead as one of the main chemical causes of health problems (Sun 2018). It can easily enter the human body via ingestion, inhalation, or skin contact (Zhou 2018, Forghani 2020). The maximum permissible level of $\mathrm{Pb}^{2+}$ in water is 0.01 $\mathrm{mg} / \mathrm{L}$. Lead intoxication commonly occurs because of accumulation in the human body due to its long half-life and non-biodegradable nature. Lead poisoning causes severe damage, such as heart disease, cancer, anemia, and liver failure, as well as gastrointestinal, kidney, and brain damage, even at very low concentrations (Wang 2016, Zhu 2019). Lead detoxification to remove hazardous metals from the human body can be carried out by several techniques, including chemical precipitation, electrochemistry, flocculation, adsorption, and membrane separation, but one of the most effective is adsorption using adsorbent materials (Zhu 2019).

Metal-organic frameworks (MOFs) are three-dimensional porous hybrid materials constructed by inorganic cluster nodes and organic ligands as the linkers. The ultrahigh porosity of MOFs makes them a great candidate as adsorbents in lead detoxification. One of the most widely-used MOFs, due to their non-toxicity and biocompatibility in biomedical applications, including drug delivery and detoxification, is $\mathrm{MIL}-100(\mathrm{Fe})\left(\mathrm{Fe} \mathrm{F}_{3} \mathrm{~F}\left(\mathrm{H}_{2} \mathrm{O}\right) \mathrm{O}\left[\mathrm{C}_{6} \mathrm{H}_{3}\left(\mathrm{CO}_{2}\right)_{3}\right]_{2} \cdot n \mathrm{H}_{2} \mathrm{O}\right)$ $(\mathrm{MIL}=$ Matériaux de 1'Institut Lavoisier) (Horcajada et al., 2007; Nguyen et al., 2019). It contains $\left[\mathrm{Fe}_{3} \mathrm{O}(\mathrm{X})\left(\mathrm{H}_{2} \mathrm{O}\right)_{2}\right]^{6+}$ clusters interconnected by 1,3,5-benzenetricarboxylate ligands that generate permanent pentagonal and hexagonal cavities ( $25 \AA$ and $29 \AA$ ) with microporous windows of 5.5 $\AA$ and $8.6 \AA$ (Bezverkhyy et al., 2016; Huo et al., 2012). In addition to the porosity, MIL-100(Fe) possesses a large surface area and high thermal and chemical stability (Shi et al., 2013; Han et al., 2017; Yuan et al., 2019). The presence of unsaturated open metal sites in the framework allows coordination with various compounds, such as EDTA.

Ethylenediaminetetraacetic acid (EDTA) is an effective chelating agent with four carboxyl and two tertiary amine sites, and it can effectively extract $\mathrm{Pb}^{2+}$ ions from contaminated soil (Lim 2005). A previous report showed that the coordination of EDTA into support materials

52 could maintain active functional sites (Wu et al., 2019). Several studies have been conducted to 53 immobilize EDTA to support materials for $\mathrm{Pb}^{2+}$ adsorption, such as EDTA-GO (Madadrang et al., 54 2012), MOF-808-EDTA (Peng et al., 2018), and UiO-66-EDTA (Wu et al., 2019), and have shown 
55 enhanced adsorption capacity. Mostly, MIL-100(Fe) is synthesized under hydrothermal or 56 solvothermal reactions in the presence of $\mathrm{HF}$ as a modulator that is not environmentally friendly 57 (Horcajada et al., 2007; Nguyen et al., 2019) and has not yet been modified with EDTA or 58 investigated for lead detoxification. Moreover, the integration of EDTA into previously mentioned 59 MOFs was achieved through the long post-synthesis method, which required high energy, longer 60 reaction time, and poor chemical stability (Wu et al., 2019; Zhang et al., 2021). In this study, we 61 successfully modified MIL-100(Fe) with EDTA in situ to open metal sites via the green 62 electrochemical method with a shorter reaction time at ambient temperature, and evaluated the 63 performance of the material in the $\mathrm{Pb}^{2+}$ detoxification.

65 Experimental

66 Materials

67 The materials used in this study were Fe electrodes (dimension $10 \times 0.1 \times 0.5 \mathrm{~cm}$; Pudak Scientific, 68 99.9\%), $\mathrm{H}_{3} \mathrm{BTC}$ (Sigma Aldrich, 95\%), EDTA-2Na (Merck, 99\%), ethanol (Sigma Aldrich, 96\%), 69 tetra-butyl ammonium tetra-fluoroborate (TBATFB) (Sigma Aldrich, 98\%), $\mathrm{Pb}^{2+}$ solution 1000 70 ppm (Merck), phosphate buffer saline (PBS) solution ( $\mathrm{pH}$ 7.2), acetone (Merck, 99\%), $\mathrm{HNO}_{3}$ 71 (Merck, 65\%), $\mathrm{NaOH}$ (Merck, 97\%), concentrated $\mathrm{HCl}$ (Mallinckrodt, 37\%), $\mathrm{NaCl}$ (Merck, 99\%), $72 \mathrm{NaHCO}_{3}$ (Riedel-deHaen, 99\%), $\mathrm{MgCl}_{2} \cdot 6 \mathrm{H}_{2} \mathrm{O}$ (Merck, 99\%), $\mathrm{CaCl}_{2}$ (Merck, 99\%), $73 \mathrm{~K}_{2} \mathrm{HPO}_{4} \cdot 3 \mathrm{H}_{2} \mathrm{O}$ (Merck, 98\%) and $\mathrm{KH}_{2} \mathrm{PO}_{4}$ (Merck, 99\%). All materials were used as purchased 74 without further purification.

\section{Synthesis of MIL-100(Fe) and MIL-100(Fe)-modified EDTA}

MIL-100(Fe) was synthesized via an electrochemical method. Fe electrodes were cleaned using sandpaper, washed with $\mathrm{HNO}_{3}(1 \mathrm{M})$, and rinsed with water. The $\mathrm{H}_{3} \mathrm{BTC}$ ligand $(0.1 \mathrm{M})$ and TBATFB electrolyte were dissolved in $50 \mathrm{~mL}$ of water: ethanol (1:1) and stirred. The Fe electrodes were then placed in a beaker containing the solvent and electrolyte mixture. Electrolysis was conducted at room temperature for $2 \mathrm{~h}$ at a voltage of $15 \mathrm{~V}$. The obtained brown solid was filtered, washed twice with ethanol to remove the residual ligand, and dried at room temperature, followed 83 by activation at $200^{\circ} \mathrm{C}$ for $2 \mathrm{~h}$.

MIL-100 (Fe)-EDTA was prepared in situ using the same method as MIL-100 (Fe) but with the addition of EDTA $\left(\mathrm{H}_{3} \mathrm{BTC}\right.$ : TBATFB: EDTA-2Na = 1:1:1). The obtained solid was 
washed with water $(2 \times 25 \mathrm{~mL})$ and ethanol $(2 \times 25 \mathrm{~mL})$, dried at room temperature, and activated 87 at $60^{\circ} \mathrm{C}$ for $12 \mathrm{~h}$.

\section{Characterization}

X-ray diffractograms were recorded using X'Pert Pro MPD with Cu K- $\alpha(\lambda=1.5418 \AA)$ radiation to observe the crystallinity and phase purity synthesized materials. FTIR spectra were measured using Shimadzu-type IR Prestige-21 to analyze the shift in functional groups of the materials. Thermogravimetry analysis was performed using Hitachi STA-7000 with a heating rate $10^{\circ} \mathrm{C} / \mathrm{min}$ under nitrogen flow. The surface area, pore volume, and pore size distribution were measured using Quantachrome QuadraSorb Station 3 Version 5.04. The SEM and TEM analyses were performed on Hitachi SU-3500 and Jeol Jem-1400, respectively, to observe the morphology of the synthesized materials.

\section{Adsorption Studies}

\section{Effectivity Test of the Adsorbent Materials}

The effectivity of the material in adsorbing $\mathrm{Pb}$ was measured by immersing $10 \mathrm{mg}$ of the

103 The mixture was shaken at $240 \mathrm{rpm}$ for $24 \mathrm{~h}$ to achieve adsorption equilibrium, and then filtered.

104 The concentration of $\mathrm{Pb}\left(\mathrm{NO}_{3}\right)_{2}$ in the filtrate was analyzed by atomic adsorption spectrometry 105 (AAS) to identify the equilibrium concentration of $\mathrm{Pb}^{2+}$ ions $\left(C_{e}\right)$. The number of the adsorbed $106 \mathrm{~Pb}^{2+}$ ions was determined from the difference between the initial concentration and equilibrium 107 concentration of $\mathrm{Pb}^{2+}$ ions in the solution. The efficiency and adsorption capacity were then 108 calculated using Equations 1 and 2 (Jin et al., 2019).

$109 q_{\mathrm{e}}=\frac{V\left(C_{\mathrm{o}}-C_{\mathrm{e}}\right)}{m}$

$110 \%$ Adsorption $=\frac{C_{\mathrm{o}}-C_{\mathrm{e}}}{C_{\mathrm{o}}} \times 100 \%$

111 where $q_{e}$ is the adsorption capacities of the ions in the adsorbent $(\mathrm{mg} / \mathrm{g}), V$ is the volume of the $112 \mathrm{~Pb}\left(\mathrm{NO}_{3}\right)_{2}$ solution $(\mathrm{L}), C_{o}$ is the initial concentration of $\mathrm{Pb}\left(\mathrm{NO}_{3}\right)_{2}$ solution $(\mathrm{mg} / \mathrm{L})$ and $C_{e}$ is the 113 equilibrium concentration of $\mathrm{Pb}\left(\mathrm{NO}_{3}\right)_{2}$ solution $(\mathrm{mg} / \mathrm{L})$.

\section{Effect of pH, Contact Time, and Initial Concentration on $\mathbf{P b}^{2+}$ Adsorption}


116 mixing $10 \mathrm{mg}$ of MIL-100(Fe)-EDTA as the adsorbent and $10 \mathrm{~mL}$ of $\mathrm{Pb}\left(\mathrm{NO}_{3}\right)_{2}$. To evaluate the

117 effect of $\mathrm{pH}, \mathrm{PBS}$ solution was added, and the $\mathrm{pH}$ was tuned to $1.2,2,3,4,5,6,6.8$, and 8.2. Using

118 the obtained optimum $\mathrm{pH}$, the optimum contact time was determined by varying the contact time

119 at 15, 30, 60 min and 3, 6, 9, 12, 15, $24 \mathrm{~h}$. The optimum initial concentration was evaluated with 120 a range of $2,5,10,20$, and $30 \mathrm{ppm}$. The mixture of adsorbent and $\mathrm{Pb}\left(\mathrm{NO}_{3}\right)_{2}$ solution was shaken 121 at $140 \mathrm{rpm}$ for $24 \mathrm{~h}$ and then filtered, and the $\mathrm{Pb}^{2+}$ content was analyzed using AAS.

122

123 Results and Discussion

124 Materials Characterization

125 X-Ray Diffraction (XRD)

MIL-100(Fe) and MIL-100(Fe)-EDTA were successfully synthesized via the

127 electrochemical method, as confirmed by XRD analysis. The diffactrogram (Figure 1 and ESI

128 Figure S1) showed similar characteristic peaks between the as-synthesized materials and the 129 standard pattern of MIL-100(Fe) (CCDC No.640536) at $2 \theta=6.29^{\circ}(511) ; 7.08^{\circ}(440) ; 10.22^{\circ}$

$130 \quad(660) ; 11.0^{\circ}(428) ; 12.74^{\circ}(1022) ; 14.83^{\circ}(088) ; 20.09^{\circ}(4814) ; 24^{\circ}(6618)$; and $27.5^{\circ}(9312)$. The 131 diffactogram of EDTA-modified MIL-100(Fe) (Figure 1) also displayed high similarity compared 132 to both MIL-100(Fe) $\left(2 \theta=6.22^{\circ}(511) ; 6.72^{\circ}(404) ; 10.22^{\circ}(660) ; 10.95^{\circ}(428) ; 12.47^{\circ}(1022)\right.$; 13314.63 (088); $20.06^{\circ}$ (4814); 24.0 (6618); and 27.90 (9321)) and EDTA-2Na (JCPDS File No. 29134 1917) $\left(2 \theta=11.03^{\circ}(020) ; 17.39^{\circ}(002) ; 26.28^{\circ}(430)\right.$; and $\left.29.25^{\circ}(422)\right)$. 


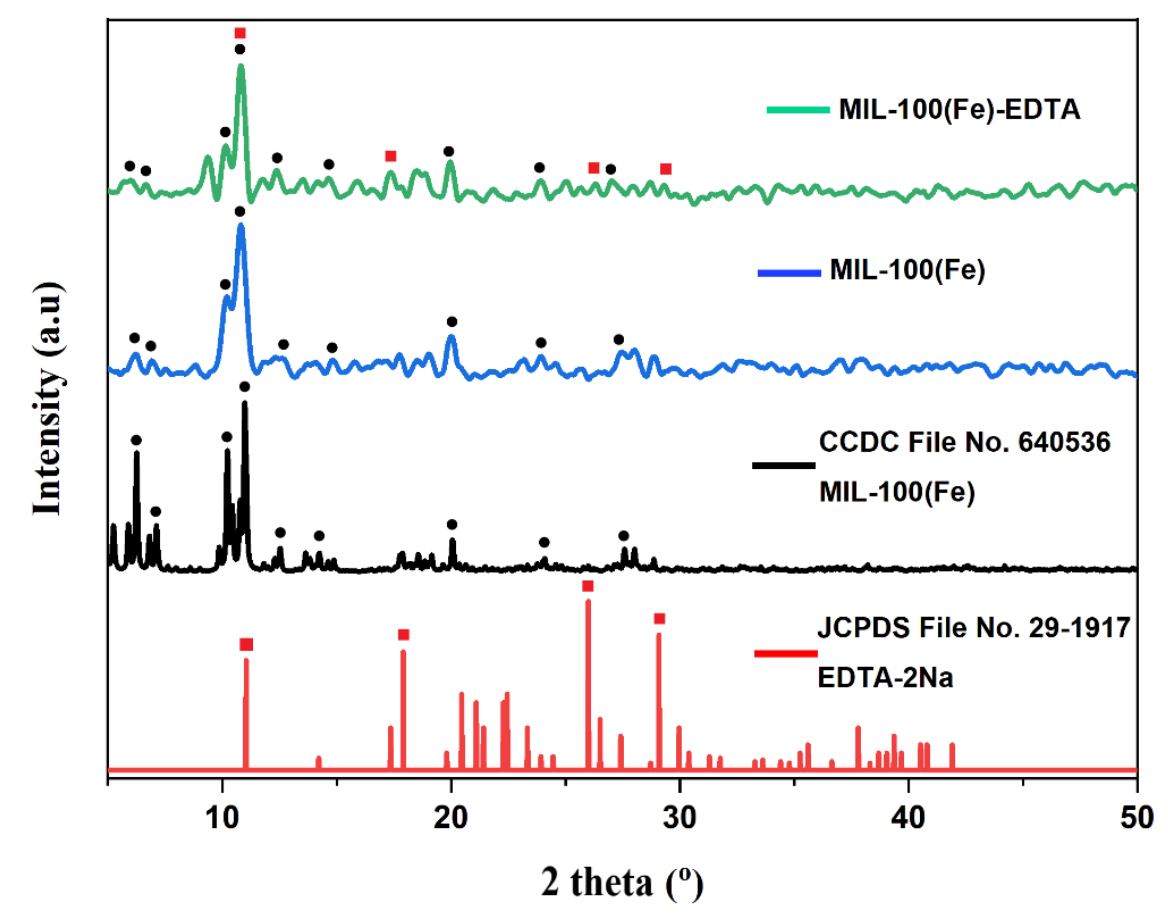

Figure 1. Diffractogram of the as-synthesized MIL-100(Fe)-EDTA compared to the assynthesized and standard pattern (CCDC No. 64053) of MIL-100(Fe) and EDTA-2Na (JCPDS No. 29-1917)

\section{Fourier Transform Infrared Spectroscopy (FTIR)}

The successful synthesis of MIL-100(Fe)-EDTA was also confirmed by FTIR analysis.

141 The characteristic bands from the $\mathrm{COOH}$ groups in $\mathrm{H}_{3} \mathrm{BTC}$ spectra $\left(\mathrm{v}_{\mathrm{OH}}, 3087 \mathrm{~cm}^{-1} ; v_{\mathrm{C}=\mathrm{O}}, 1719\right.$

$142 \mathrm{~cm}^{-1} ; \delta_{\mathrm{C}=0}, 1275-1109 \mathrm{~cm}^{-1}$ ) disappeared and shifted in the MIL-100(Fe) spectra (Maiti et al.,

143 2015). As depicted in Figure 2, the absorption band of carboxyl groups $(\mathrm{C}=\mathrm{O})$ shifted from 1719

$144 \mathrm{~cm}^{-1}$ to $1623 \mathrm{~cm}^{-1}$, indicating the deprotonation of the ligand and coordination with $\mathrm{Fe}^{3+}$ ions,

145 which was also supported by the presence of the absorption band of Fe-O bonds at $473 \mathrm{~cm}^{-1}$. The 146 change in the absorption of O-H carboxyl from $3087 \mathrm{~cm}^{-1}-2553 \mathrm{~cm}^{-1}$ in $\mathrm{H}_{3} \mathrm{BTC}$ to $3403-3084 \mathrm{~cm}^{-}$

$147{ }^{1}$ in the as-prepared MIL-100(Fe) indicated the formation of molecular bonds between $\mathrm{H}_{2} \mathrm{O}$ and $148 \mathrm{Fe}^{3+}$ ions. Vibration bands of the O-C-O groups were observed at $1445-1377 \mathrm{~cm}^{-1}$, and the absence 149 of $\mathrm{C}=\mathrm{O}$ stretching vibration in the MIL-100(Fe) spectra showed that the residual ligand was 150 completely removed by the ethanol washing procedure (Huang et al., 2017). 
152 unmodified MOFs. New peaks were observed at $1005 \mathrm{~cm}^{-1}, 2876 \mathrm{~cm}^{-1}$ and $2964 \mathrm{~cm}^{-1}$ that 153 represented C-N, C-H, and N-H bonds, confirming the coordination of EDTA in MIL-100(Fe) 154 (Zhang et al., 2019). The relatively low peaks of C-N bonds at $1042-1000 \mathrm{~cm}^{-1}, \mathrm{C}-\mathrm{H}$ bonds at $1552890-2850 \mathrm{~cm}^{-1}$ and N-H bonds at 2990-2940 $\mathrm{cm}^{-1}$ in the MIL-100(Fe)-EDTA spectra resembled 156 the small amount of EDTA added to the MOFs.

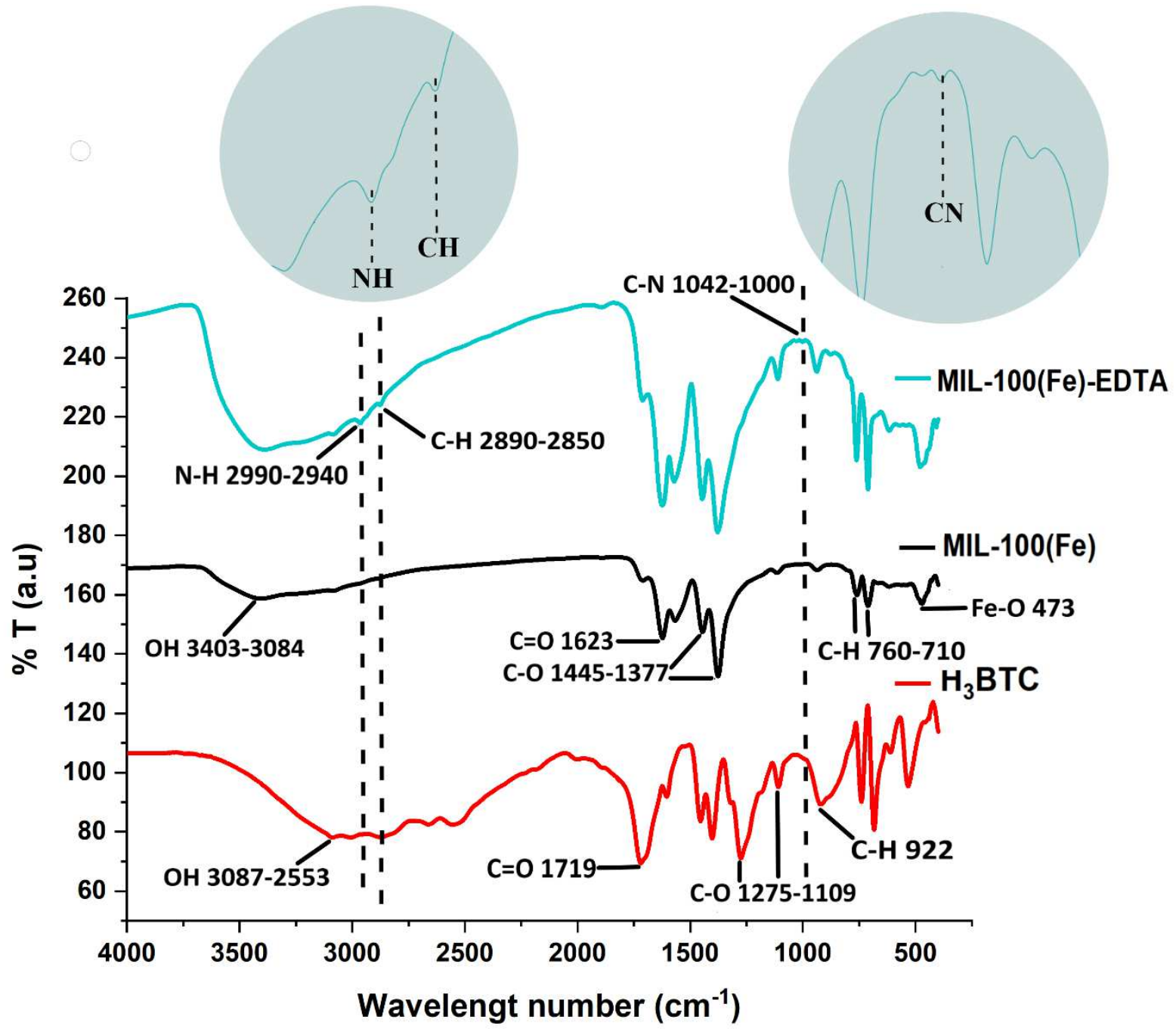




\section{Thermo Gravimetric Analysis (TGA)}

163

Thermal stability of the materials was measured using thermogravimetry analysis (TGA), revealing three mass losses in the temperature range of $25-500^{\circ} \mathrm{C}$ (see ESI Figure S2). The first mass loss of $24.9 \%$ and $23.3 \%$ for MIL-100(Fe) and MIL-100(Fe)-EDTA, respectively, occurred at $25-150^{\circ} \mathrm{C}$ and was related to the evaporation of water and ethanol solvents both on the surface and within the porosity of the materials. Further calculations showed that 12 and 15 molecules of water were removed from MIL-100(Fe) and MIL-100(Fe)-EDTA, respectively.

A second mass loss was observed at $100-348^{\circ} \mathrm{C}$, with a loss of $4.5 \%$ and $5.3 \%$ for MIL$100(\mathrm{Fe})$ and MIL-100(Fe)-EDTA, respectively, indicating the removal of the two and three water molecules coordinated to the Fe trimmers. This is in agreement with the structure of MIL-100(Fe), which binds two water molecules (Abednatanzi et al., 2017). In the MIL-100(Fe)-EDTA, the second mass loss also corresponded to the removal of EDTA. According to Narayanan et al. (2015), EDTA began to decompose at $230-320^{\circ} \mathrm{C}$, resulting in a mass loss of up to $70 \%$. The third mass loss at $300-500^{\circ} \mathrm{C}$ was $28.4 \%$ for MIL-100(Fe) and $25.1 \%$ for MIL-100(Fe)-EDTA, which was associated with the degradation of the frameworks. The total mass loss of MIL-100(Fe)-EDTA was slightly lower than that of MIL-100(Fe) due to the attachment of EDTA. Overall, the TG curve showed that the thermal stability of the materials was up to $308^{\circ} \mathrm{C}$ for $\mathrm{MIL}-100(\mathrm{Fe})$ and $348^{\circ} \mathrm{C}$ for MIL-100(Fe)-EDTA. The higher stability of MIL-100(Fe)-EDTA is related to the strong coordination between the metal nodes and carboxyl groups in EDTA (Abednatanzi et al., 2017).

\section{Scanning Electron Microscopy-Energy Dispersive X-ray (SEM-EDX) and Transmition}

\section{Electron Microscopy (TEM)}

The morphology of the synthesized materials was analyzed using SEM-EDX and TEM. A study by Forghani et al. (2020) demonstrated that MIL-100(Fe) occupies octahedral geometry, whereas in this study, it showed an irregular shape, as seen from the results of SEM imaging (Figure 3a). Seo et al. (2012) reported that the use of HF in the synthesis of MIL-100(Fe) could improve the crystallinity since the $\mathrm{F}^{-}$anions have the capability to stabilize the $\mathrm{Fe}^{3+}$. However, the electrochemical method we used in this study did not include HF as a modulator, which is the reason for the irregular morphology of the products. In this case, $\mathrm{F}^{-}$anions were replaced by hydroxyl anions (from water) to balance the charge of $\mathrm{Fe}^{3+}$. 


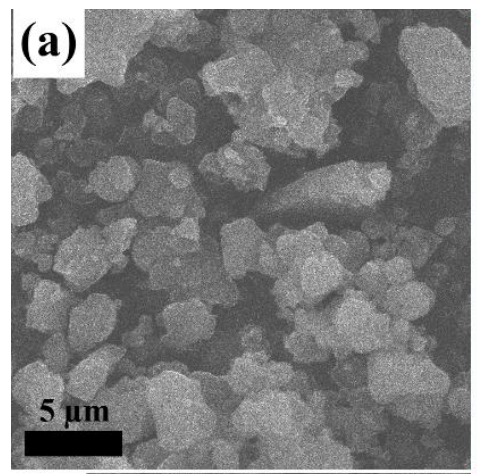

\section{(b)}

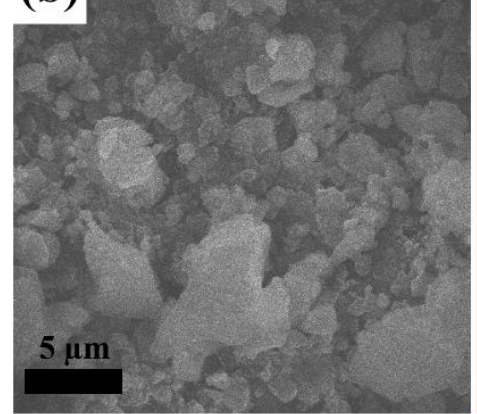

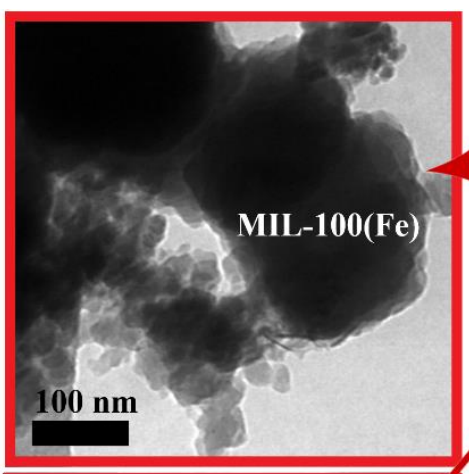

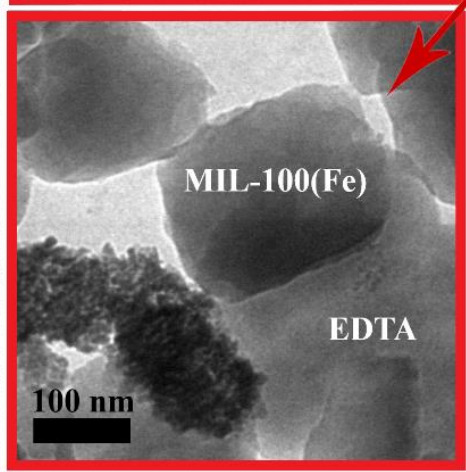

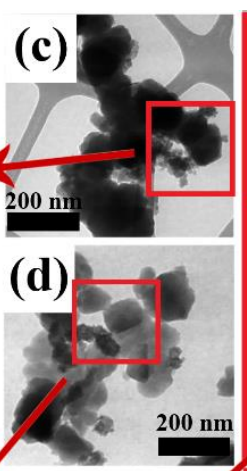
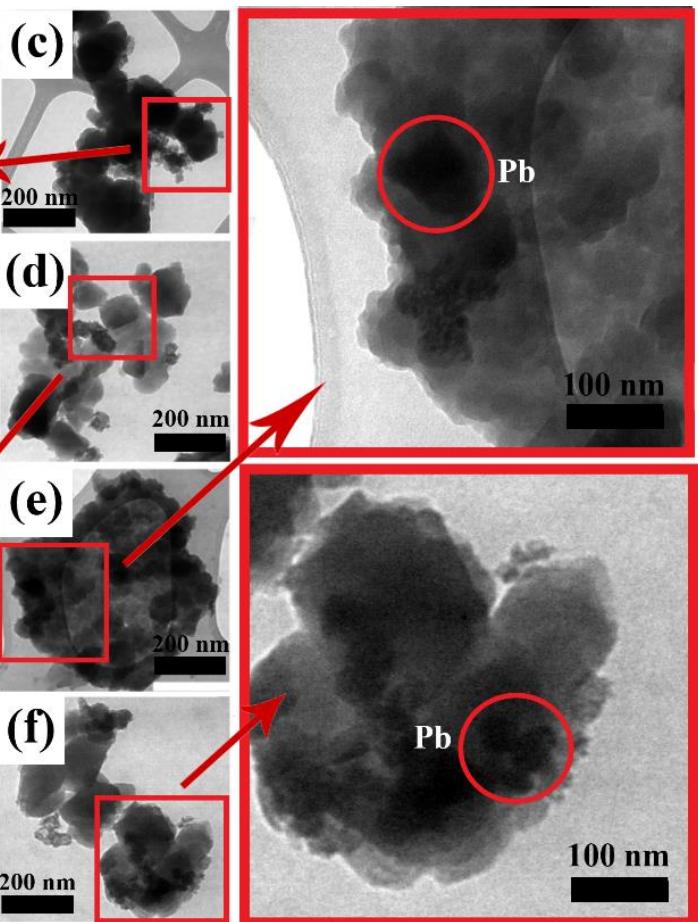

Figure 3. SEM imaging of MIL-100(Fe) (a) and MIL-100(Fe)-EDTA (b) TEM imaging of MIL100(Fe) (c) and MIL-100(Fe)

Fe)-EDTA

(d) TEM imaging of MIL-100(Fe)

Fe) (e) and MIL-100(Fe)EDTA (f) after $\mathrm{Pb}^{2+}$ ions adsorption (red circle shows the presence of $\mathrm{Pb}^{2+}$ )

As shown in Figure 3b, the EDTA modification yielded no significant difference in the morphology but slightly increased the particle size. The average particle sizes of MIL-100(Fe) and MIL-100(Fe)-EDTA were $0.90 \pm 0.30 \mu \mathrm{m}$ and $0.94 \pm 0.32 \mu \mathrm{m}$, respectively. The histogram of particle size distribution showed that the particle size ranged from 0.29 to $1.68 \mu \mathrm{m}$ for MIL100(Fe) and from 0.31 to $1.72 \mu \mathrm{m}$ for MIL-100(Fe)-EDTA (see ESI Figure S3). The particle size of the materials in this study was smaller than those reported in the literature, which ranged from 0.4 to $8.6 \mu \mathrm{m}$ (Lestari et al., 2016).

The TEM images, however, showed that the geometry of both MIL-100(Fe) and MIL-

204 (Figure 3d) revealed that some of the MIL-100(Fe) were planted around the EDTA according to 205 the number of EDTA added in the reaction. This indicates that EDTA was coordinated into the surface of MIL-00(Fe). The histogram in ESI Figure S4 demonstrates that the particle size of MIL-

$207100(\mathrm{Fe})$ ranged from 137 to $227 \mathrm{~nm}$, whereas for MIL-100(Fe)-EDTA, it was 127-203 nm. The 208 morphology of both materials showed no significant change after exposure to the $\mathrm{Pb}$ (II) solution 
209 during the adsorption process (Figure 3e). The successful adsorption of $\mathrm{Pb}$ was proven by the 210 entrapped $\mathrm{Pb}(\mathrm{II})$ molecules within the MOFs, shown in the red circles in Figure 3f, with no change 211 in the morphology of the host material. This phenomenon shows that MIL-100(Fe) and MIL$212100(\mathrm{Fe})-E D T A$ can be used as adsorbents (detoxification agent) for $\mathrm{Pb}^{2+}$ metal ions.

\section{Surface Area Analyzer (SAA)}

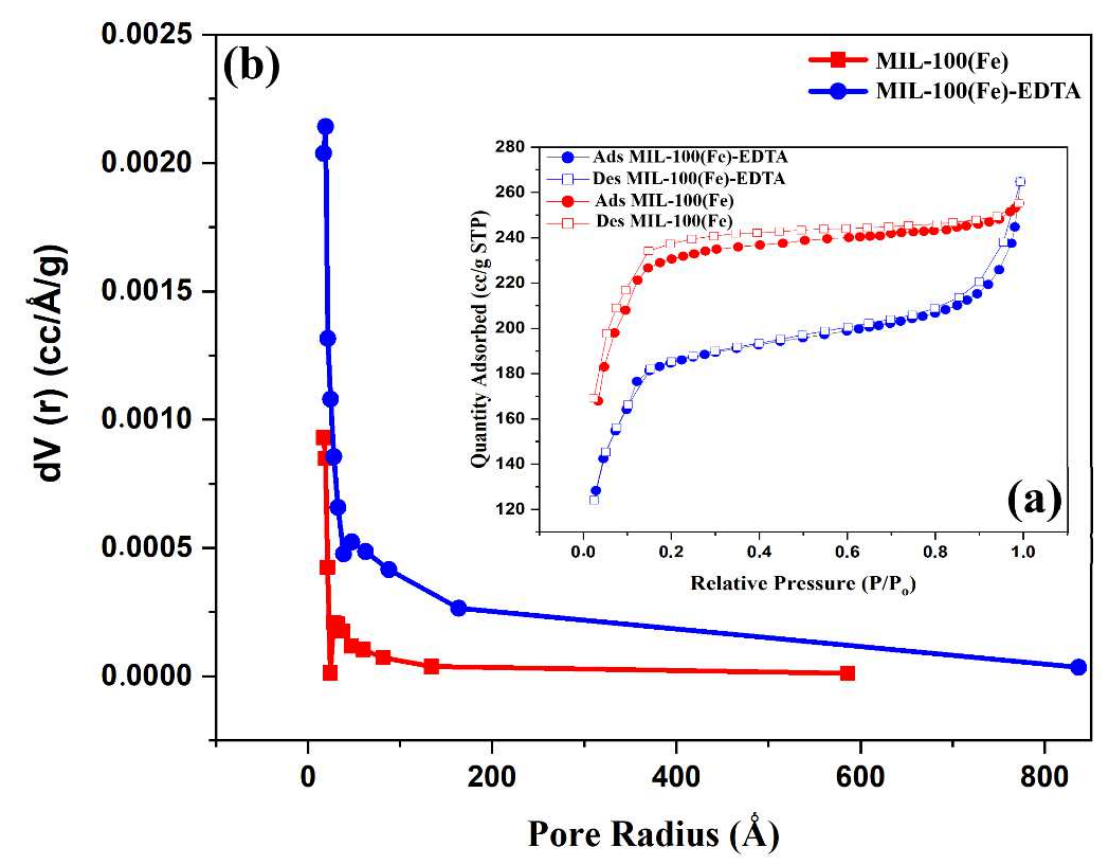

215 Figure 4. Nitrogen sorption isotherm (a) and pore size distribution (b) of MIL-100(Fe) and MIL100(Fe)-EDTA

218 100(Fe)-EDTA, according to the IUPAC classification, followed a type I isotherm that indicated 219 microporosity (Figure 4a). MIL-100(Fe) had the BET surface area of $722.433 \mathrm{~m}^{2} / \mathrm{g}$ and pore 220 volume of $0.025 \mathrm{cc} / \mathrm{g}$. Its surface area is higher than that of MIL-100(Fe) synthesized by Lestari et 221 al. (2016), but the pore volume is lower (surface area of $569.191 \mathrm{~m}^{2} / \mathrm{g}$ with pore volume of 0.4540 $222 \mathrm{cc} / \mathrm{g}$ ). The addition of EDTA to MIL-100(Fe) decreased its BET surface area to $587.253 \mathrm{~m}^{2} / \mathrm{g}$. 223 Thus is in accordance with the report by Wu et al. (2019) that demonstrated the same phenomenon, 224 since the EDTA molecules block the porosity of MOFs. However, the surface area is still larger 225 than other adsorbent materials, such as polyethylenimine-modified activated carbon $\left(363 \mathrm{~m}^{2} / \mathrm{g}\right)$ 226 (Saleh et al., 2017), silica/lignin (223 m²/g) (Klapiszewsk et al., 2015), $\mathrm{Al}_{2} \mathrm{O}_{3}\left(346 \mathrm{~m}^{2} / \mathrm{g}\right)$ 
227 (Akarmazyan et al., 2014), and ascorbic acid- $\mathrm{Fe}_{3} \mathrm{O}_{4}(178 \mathrm{~m} / \mathrm{g}$ ) (Feng et al., 2012). However, its 228 porosity slightly increased to $0.128 \mathrm{cc} / \mathrm{g}$. The micropore size in the materials was also measured 229 using the Barrett, Joyner and Halenda $(\mathrm{BJH})$ method. Figure $4 \mathrm{~b}$ illustrates the pore size distribution 230 of MIL-100(Fe) and MIL-100(Fe)-EDTA, revealing a pore radius of $1.7 \mathrm{~nm}$ and $1.9 \mathrm{~nm}$ for both 231 materials, respectively.

\section{Stability Test of Materials in the Intestinal and Stomach Simulation Medium and Water}

The stability of MIL-100(Fe) and MIL-100(Fe)-EDTA was tested in a water medium at

$234 \mathrm{pH}$ 7, Ringer's solution at $\mathrm{pH} 6$ to simulate the intestinal medium, and a hydrochloride acid 235 solution $(\mathrm{HCl})$ at $\mathrm{pH} 1.2$ to simulate the stomach medium, according to the procedure described 236 by Rojas et al., (2018). The FTIR spectra for the materials in the corresponding mediums after a 237 period ( $24 \mathrm{~h}$ for intestinal simulation and $2 \mathrm{~h}$ for stomach simulation at room temperature) 238 demonstrated no significant change (see ESI Figure S5). The new absorption band appearing in 239 the intestinal simulation spectra is a result of the presence of $\mathrm{PO}_{4}{ }^{3-}$ ions in the intestine 240 (Mobasherpour et al., 2007; Rojas et al., 2018).

241 The XRD of the materials after the stability test also validated the results. As shown in 242 Figure 5, the characteristic peak at $2 \theta=11^{\circ}$ for each material was maintained after contact with 243 the mediums (Forghani et al., 2020), proving that the materials have high stability. However, in 244 the intestinal simulation medium, the peaks of both MIL-100(Fe) and MIL-100(Fe)-EDTA 245 displayed different intensities when compared to the other medium. This is because in the digestion 246 system, various ions (such as phosphate in the intestine), enzymes, and entities compete with the 247 building blocks of the frameworks, thus decreasing their crystallinity (Rojas et al., 2018). 

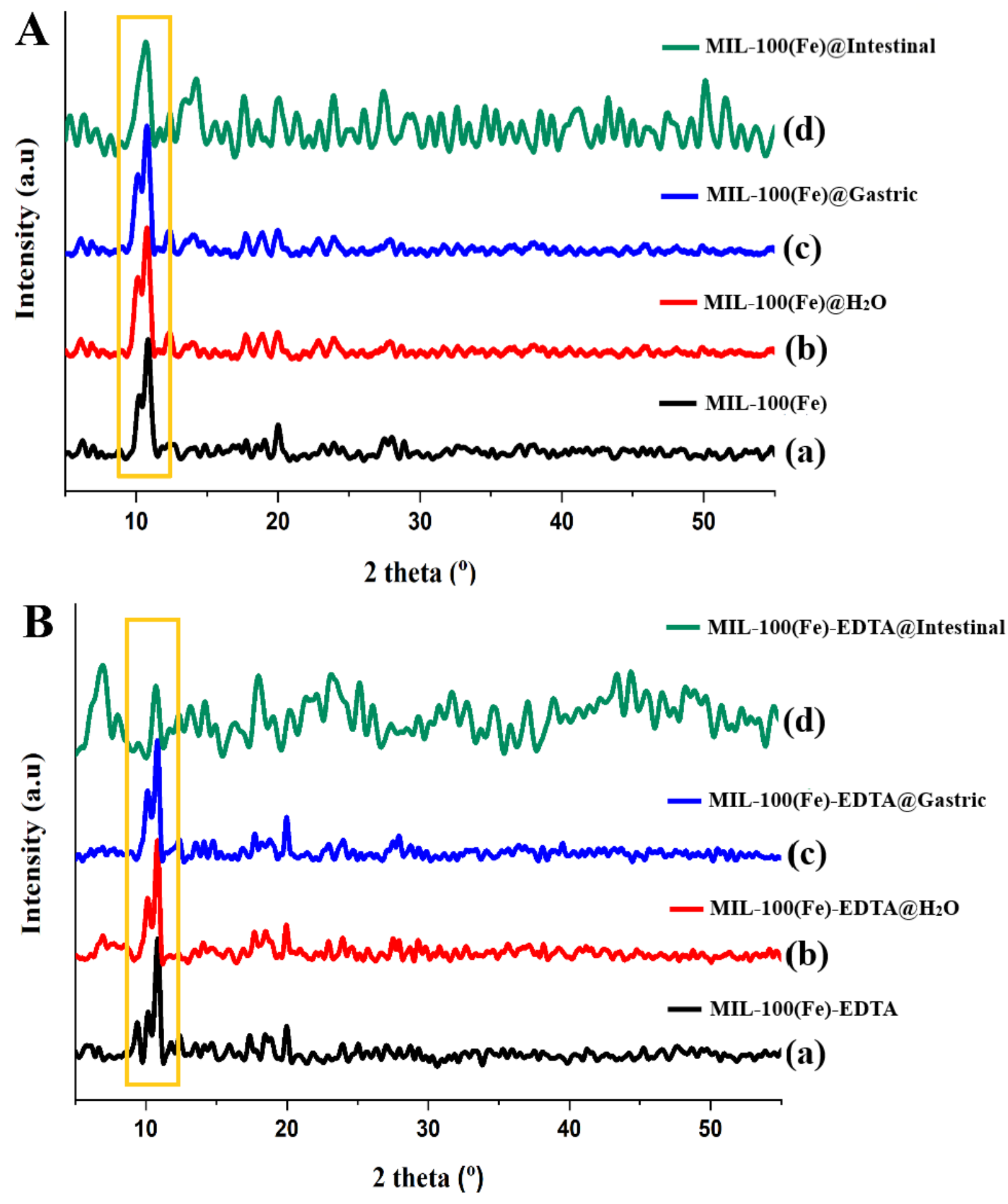

Figure 5. X-Ray diffractograms of MIL-100(Fe) (A) and MIL-100(Fe)-EDTA (B): initial 251 materials (a) and after the stability test in water medium (b), stomach simulation medium (c), and intestinal simulation medium (d) 


\section{Lead Removal Study}

A preliminary effectivity test was conducted to evaluate the adsorption efficiency and capacity of MIL-100(Fe) and MIL-100(Fe)-EDTA to detoxify $\mathrm{Pb}^{2+}$ by immersing the materials in $\mathrm{Pb}\left(\mathrm{NO}_{3}\right)_{2}$ solution $(5 \mathrm{ppm})$ at $\mathrm{pH} 1.2$ for $24 \mathrm{~h}$ after adsorption equilibrium was achieved. The results are depicted in Figure 5.

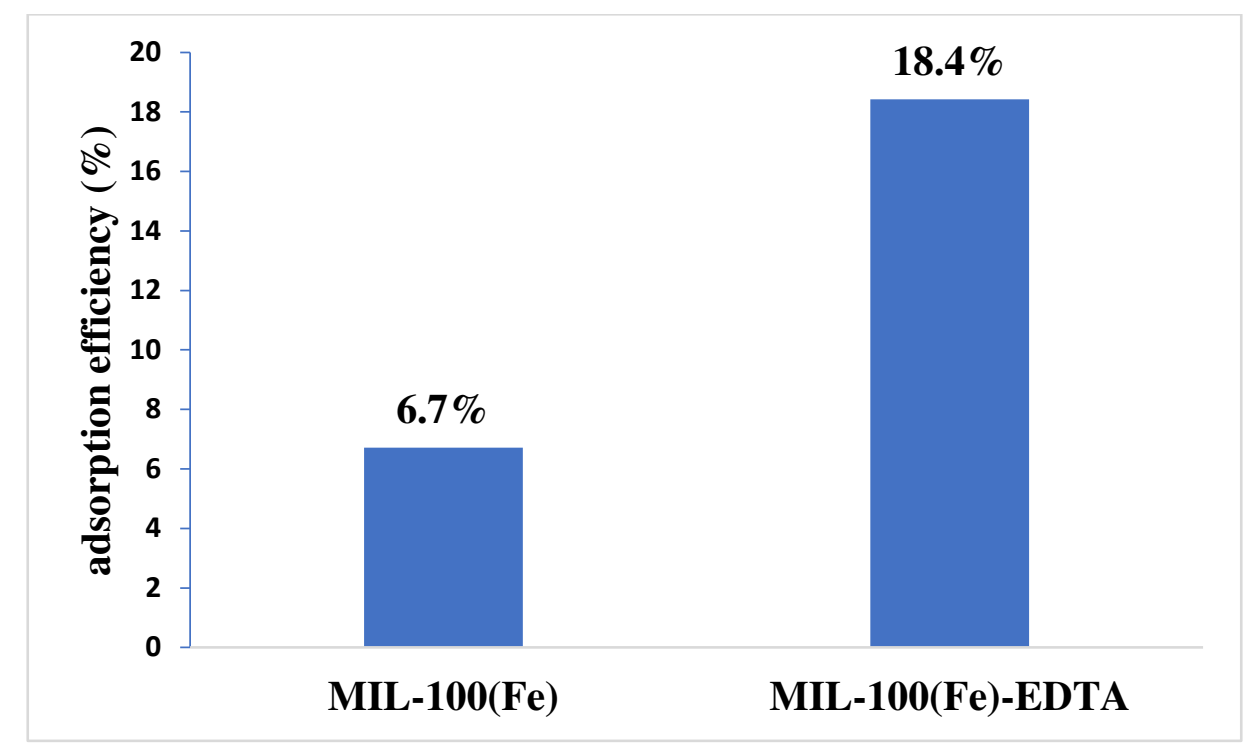

Figure 6. Adsorption efficiency of MIL-100(Fe) and MIL-100(Fe)-EDTA against $\mathrm{Pb}^{2+}$ in $\mathrm{Pb}\left(\mathrm{NO}_{3}\right) 5 \mathrm{ppm}$ solution for $24 \mathrm{~h}$ 100(Fe). The efficiency of MIL-100(Fe)-EDTA was almost three times higher than that of MIL$100(\mathrm{Fe})$, with adsorption capacities of $0.87 \mathrm{mg} / \mathrm{g}$ and $0.32 \mathrm{mg} / \mathrm{g}$ for both materials, respectively.

267 The higher adsorption capacity found in MIL-100(Fe)-EDTA may be related to the presence of 268 the chelating agent EDTA, which forms a strong chelation with $\mathrm{Pb}^{2+}$ ions (Peng et al., 2018). In 269 addition, the carboxyl groups from EDTA increase the number of active sites in the MOFs, hence 270 improving the adsorption capacity (Luo et al., 2015). The interaction between MIL-100(Fe)- 
271 EDTA with $\mathrm{Pb}^{2+}$ ions is illustrated in Figure 7, in which every EDTA molecule acts as a Lewis 272 base and binds to one $\mathrm{Pb}^{2+}$ ion (Peng et al., 2018).

273

274<smiles>O=C(O)CN(CCN(CC(=O)O)CC(=O)O[PH3+])CC(=O)O</smiles>

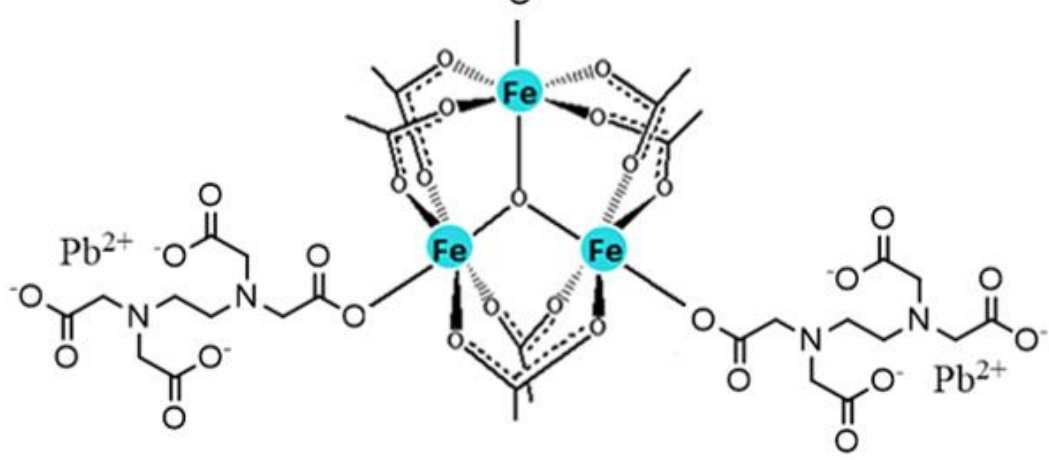

275

Figure 7. Predicted interaction between MIL-100(Fe)-EDTA and $\mathrm{Pb}^{2+}$ ions

276

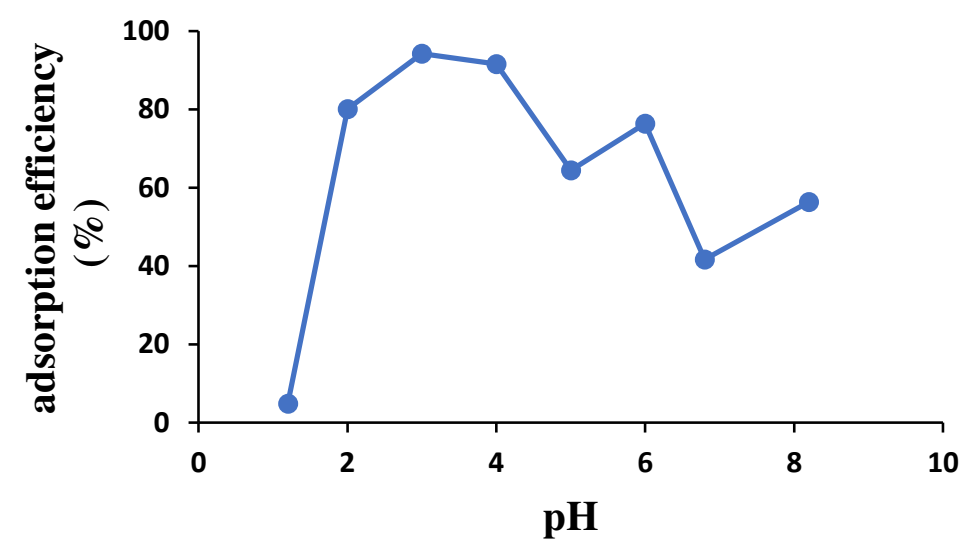

Figure 8. Effect of $\mathrm{pH}$ on the $\mathrm{Pb}^{2+}$ ions adsorption efficiency

One of the critical parameters in the adsorption process is the $\mathrm{pH}$ of the solution. Initial $\mathrm{pH}$ determination is mandatory since it could affect the chemical properties of the adsorbent and

281 the ion species existing in the solution (Zhou et al., 2018). The effect of $\mathrm{pH}$ is also correlated with 282 the ionization state of the functional groups in the adsorbent, which further affects the number of 
283 active binding sites (Elsayed et al., 2016). The results of the $\mathrm{Pb}$ adsorption efficiency of MIL$284100(\mathrm{Fe})$-EDTA with varied $\mathrm{pH}$ levels of 1.2, 2, 2.3, 4, 5, 6, 6.8, and 8.2 for $24 \mathrm{~h}$ are shown in 285 Figure 8.

The optimum condition was achieved at a $\mathrm{pH}$ of 3 , with adsorption efficiency and capacity 287 of $94.24 \%$ and $1.63 \mathrm{mg} / \mathrm{g}$, respectively, while the lowest efficiency was found at a $\mathrm{pH}$ of 1.2 . This 288 is because at a lower $\mathrm{pH}$, the $\mathrm{H}^{+}$ions compete with the $\mathrm{Pb}^{2+}$ ions to interact with the adsorbent,

289 leading to lower adsorption. Beyond $\mathrm{pH} \mathrm{1.2,} \mathrm{however,} \mathrm{the} \mathrm{trend} \mathrm{followed} \mathrm{that} \mathrm{of} \mathrm{a} \mathrm{previous} \mathrm{study}$ 290 in which the maximum adsorption efficiency of $\mathrm{Pb}^{2+}$ ions was found at low $\mathrm{pH}$, and the value 291 decreased as the $\mathrm{pH}$ increased. The decreasing adsoption efficiency at increasing $\mathrm{pH}$ showed that 292 the adsorption mechanism most likely occurred via chemical interaction or substitution process 293 instead of electrostatic forces (Goyal et al., 2021). The optimum adsorption of $\mathrm{Pb}^{2+}$ in $\mathrm{MIL}-$ $294100(\mathrm{Fe})$, as reported previously by Forghani et al. (2020), was $\sim 65 \%$ at a $\mathrm{pH} 5.5$. Greater $\mathrm{Pb}^{2+}$ 295 adsorption efficiency of MIL-100(Fe)-EDTA supports the previous result that EDTA increases the 296 number of active sites of the adsorbent and consequently improves the adsorption capacity. 297 Fluctuated curve at a $\mathrm{pH}$ range of $4-8.2$ is related to the structure of the MOFs that have 298 characteristic acid and base sites that could be activated by tuning the $\mathrm{pH}$ (Rivera et al., 2016).

\section{Effect of Contact Time}

The adsorption performance of MIL-100(Fe)-EDTA was evaluated as a function of time.

302 Measurement was conducted in $10 \mathrm{~mL}$ of $\mathrm{Pb}\left(\mathrm{NO}_{3}\right)_{2}$ solution (5 ppm) at an optimum $\mathrm{pH}$ of 3, with 303 a treatment period that ranged from $15 \mathrm{~min}$ to $24 \mathrm{~h}$. Adsorption efficiency tended to rise as the 304 contact time increased, dropping at $6 \mathrm{~h}$ and remaining constant after $24 \mathrm{~h}$ (Figure 9). Equilibrium 305 was achieved at $12 \mathrm{~h}$ with efficiency and capacity of $82.79 \%$ and $3.23 \mathrm{mg} / \mathrm{g}$. After $12 \mathrm{~h}$, no 306 significant change was observed, indicating that $\mathrm{Pb}^{2+}$ ions fully occupied the active sites of the 307 adsorbent material. 


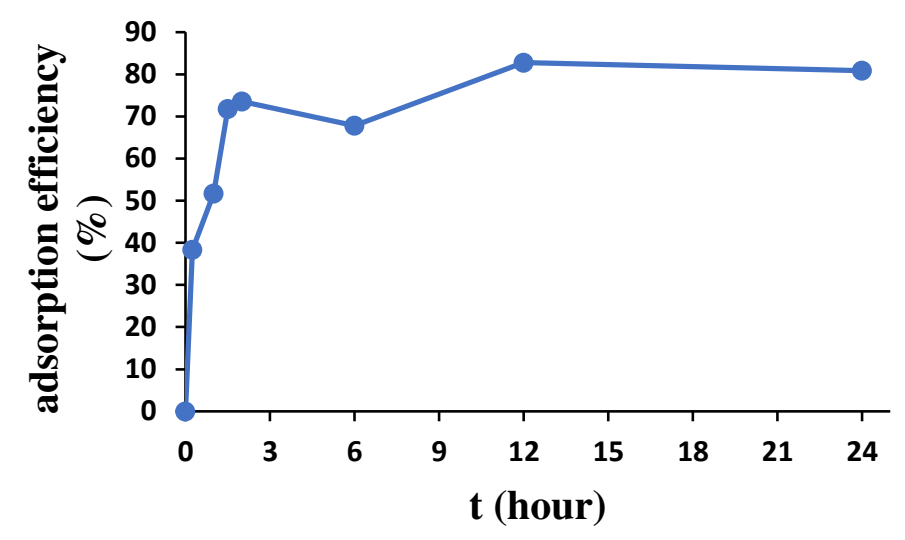

Figure 9. Effect of contact time on the $\mathrm{Pb}^{2+}$ ions adsorption efficiency

\section{Effect of Lead Concentration}

313 Different concentrations of $\mathrm{Pb}\left(\mathrm{NO}_{3}\right)_{2}$ solutions, 2, 5, 10, 20, and $30 \mathrm{ppm}$, were prepared

314 to compare the effect of the initial concentration on adsorption efficiency and capacity of the

315 MOFs, as profiled in Figure 10. High adsorption of up to 86.65\% was observed in the solution

316 with an initial concentration of $5 \mathrm{ppm}$.

317 The adsorption capacity increased significantly with increasing concentrations of $\mathrm{Pb}^{2+}$, as

318 indicated by the large number of ions adsorbed per area of adsorbent. Furthermore, the large

319 number of ions is also the driving force for the transfer of $\mathrm{Pb}^{2+}$ ions from the solution to the

320 adsorbent (Goyal et al., 2021). By contrast, the adsorption efficiency decreased as the

321 concentration of $\mathrm{Pb}^{2+}$ increased due to the competition among the overcrowded $\mathrm{Pb}^{2+}$ ions. At a

322 lower concentration, the $\mathrm{Pb}^{2+}$ ions were readily adsorbed into the adsorbent. However, at higher

323 concentrations, the adsorption rate was reduced due to intraparticle diffusion and competition

324 among the crowded $\mathrm{Pb}^{2+}$ ions (Obike et al., 2018). 


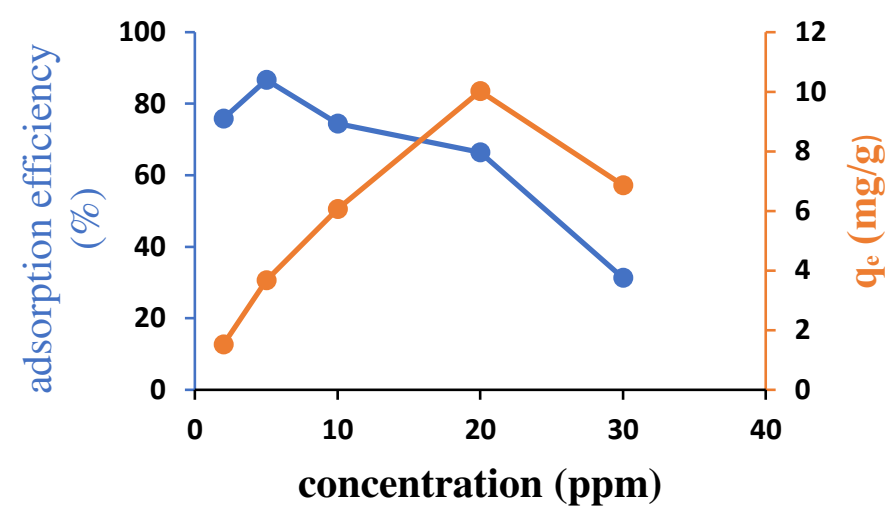

326 Figure 10. Effect of the initial concentration of $\mathrm{Pb}^{2+}$ ions on adsorption efficiency and capacity

\section{Adsorption Kinetics}

328 To identify the adsorption rate and mechanism of $\mathrm{Pb}^{2+}$ in MIL-100(Fe)-EDTA, kinetic 329 methods, including pseudo-first order and pseudo-second order, were investigated using time 330 variations. The adsorption kinetic curves are presented in Figure 11, and the parameters are shown 331 in Table 1.

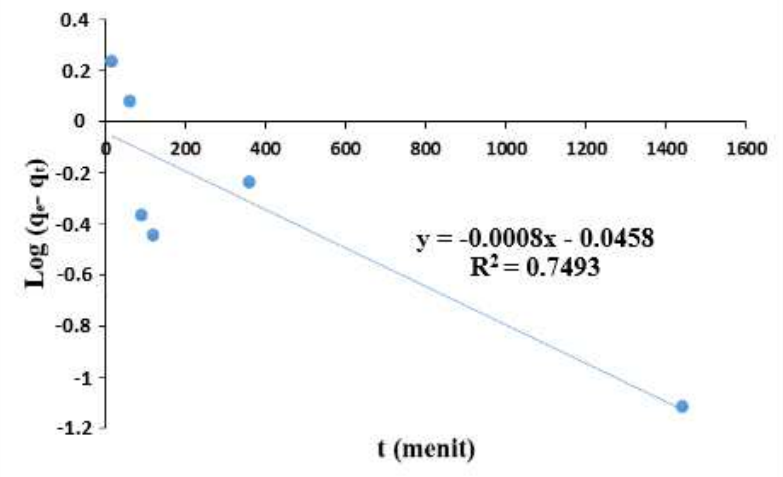

(a)

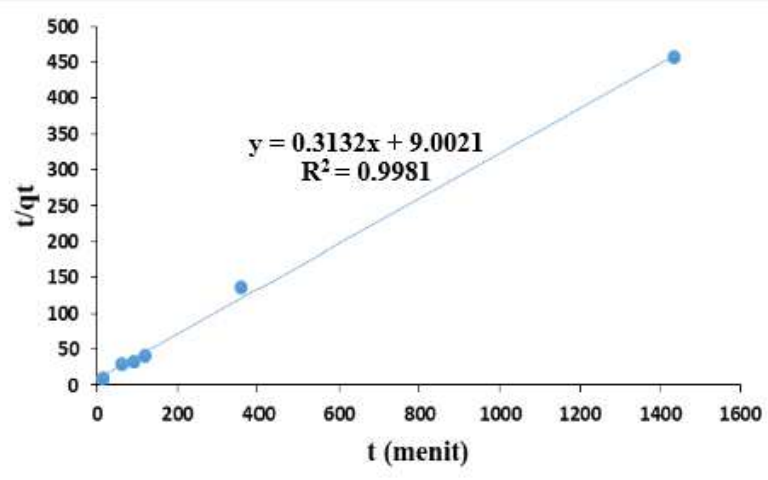

(b)

333 Figure 11. Adsorption kinetic curves for pseudo-first order (a) and pseudo-second order (b) $\mathrm{Pb}^{2+}$ ions in MIL-100(Fe)-EDTA

$338 \log \left(q_{e}-q_{t}\right)=\log q_{e}-\frac{k_{1}}{2,303} t$ 
$339 \frac{t}{q_{\mathrm{t}}}=\frac{1}{k_{2} q_{\mathrm{e}}{ }^{2}}+\frac{1}{q_{\mathrm{e}}} t$

340 where $\mathrm{q}_{\mathrm{e}}$ and $\mathrm{q}_{\mathrm{t}}(\mathrm{mg} / \mathrm{g})$ are the adsorption amount of $\mathrm{Pb}$ (II) on adsorbents at an equilibrium state 341 and at the time of $\mathrm{t}(\mathrm{min}) ; \mathrm{k}_{1}(1 / \mathrm{min})$ and $\mathrm{k}_{2}(\mathrm{~g} /(\mathrm{mg} \cdot \mathrm{min}))$ are rate constants of the pseudo-first342 order and pseudo-second-order kinetics models.

343 Table 1. Adsorption kinetic model parameters of $\mathrm{Pb}^{2+}$ ions in MIL-100(Fe)-EDTA

\begin{tabular}{ccc|ccc}
\hline \multicolumn{2}{c|}{ Pseudo-first order kinetics } & \multicolumn{3}{c}{ Pseudo-second order kinetics } \\
\hline $\mathrm{k}$ & $\mathrm{q}$ & $\mathrm{R}^{2}$ & $\mathrm{k}$ & $\mathrm{q}$ & $\mathrm{R}^{2}$ \\
$\left(\mathrm{~min}^{-1}\right)$ & $(\mathrm{mg} / \mathrm{g})$ & & $(\mathrm{g} / \mathrm{mg} \cdot \mathrm{min})$ & $(\mathrm{mg} / \mathrm{g})$ & \\
0.0018 & 0.8999 & 0.7493 & 0.0109 & 3.1928 & 0.9981 \\
\hline
\end{tabular}

The correlation coefficient, $\mathrm{R}^{2}$, for the pseudo-first order and pseudo-second order 347 adsorption kinetic followed a pseudo-second order. This kinetic model describes the adsorption 348 rate as the function of adsorption capacity and suggests that the adsorption mechanism occurs via 349 chemisorption, involving electron transfer between the adsorbates and adsorbents, or in this case, 350 complexation of $\mathrm{Pb}^{2+}$ ions with MIL-100(Fe)-EDTA (Fang et al., 2014). The low $\mathrm{k}_{2}$ showed that 351 the adsorption rate decreased with decreasing unoccupied sites number and increasing time (El352 Sayed et al., 2016).

353 A kinetic study by Forghani et al. (2020) demonstrated that $\mathrm{Pb}^{2+}$ ions adsorption by MIL$354100(\mathrm{Fe})$ followed the pseudo-first order model with total capacity at equilibrium up to $10.53 \mathrm{mg} / \mathrm{g}$ 355 that indicated weak physisorption (Tanzifi et al., 2017). Compared to MIL-100(Fe), the adsorption 356 efficiency in MIL-100(Fe)-EDTA was much higher due to the strong chelation between $\mathrm{Pb}^{2+}$ ions 357 and EDTA.

\section{Adsorption Isotherms}

Experimental data were also analyzed using two-parameter isotherm models, Langmuir 361 and Freundlich, to further investigate the interaction between $\mathrm{Pb}^{2+}$ and the adsorbent. The 362 adsorption isotherm was calculated, and the results are described in Figure 12 and Table 2. 


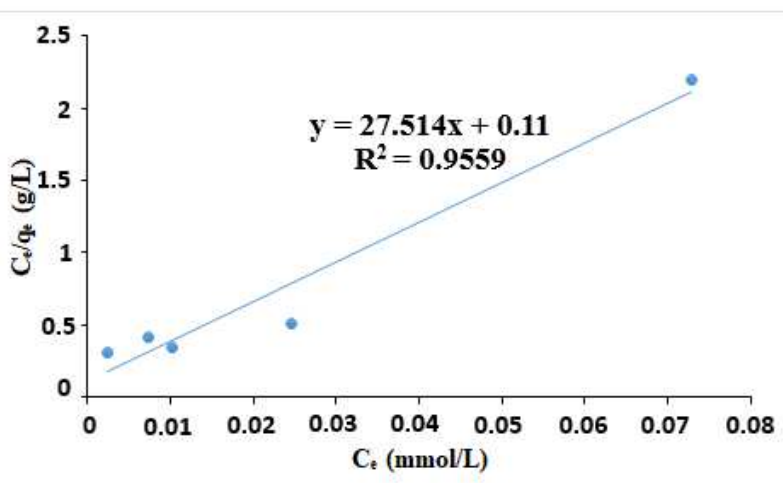

(a)

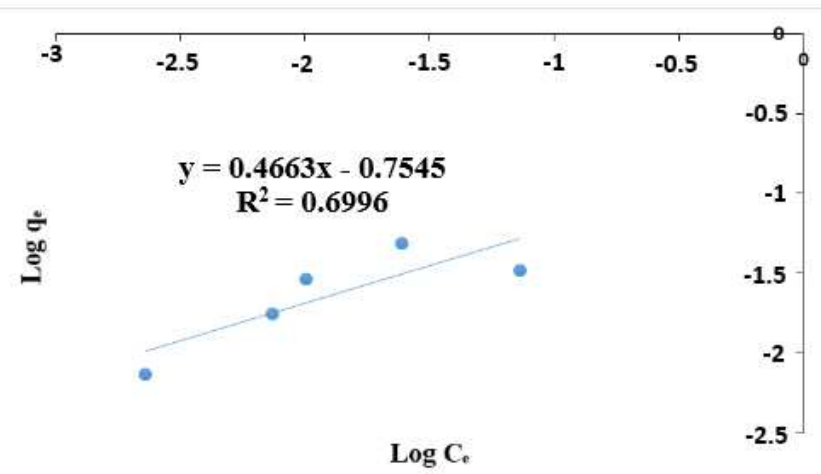

(b)
364

365

366

367

368

369

370

371

372

373

374

375

376

377

378

379

380

381

378

Figure 12. Adsorption isotherm of $\mathrm{Pb}^{2+}$ adsorbed onto MIL-100(Fe)-EDTA using Langmuir (a) and Freundlich (b) models

The equation model used to describe adsorption isotherm data is the Langmuir and Freundlich adsorption isotherm models. Equation (5) shows the Langmuir adsorption isotherm:

$$
\frac{1}{q_{\mathrm{e}}}=\frac{1}{q_{\max }}+\frac{1}{q_{\max } K_{1} C_{\mathrm{e}}}
$$

where $\mathrm{q}_{\mathrm{e}}$ is the adsorption amount of $\mathrm{Pb}(\mathrm{II})$ on adsorbents $(\mathrm{mg} / \mathrm{g})$ at an equilibrium state, $\mathrm{q}_{\max }$ is the adsorption capacity of metals on adsorbents $(\mathrm{mg} / \mathrm{g}), \mathrm{C}_{\mathrm{e}}$ is the equilibrium concentration of metals $\left(\mathrm{mg} / \mathrm{g}\right.$ ), and $\mathrm{K}_{1}$ is the Langmuir adsorption constant related to adsorption energy. The Freundlich model is shown in Equation (6):

$$
q_{\mathrm{e}}=K f C_{\mathrm{e}}{ }^{1 / n}
$$

where $\mathrm{q}_{\mathrm{e}}$ is the adsorption amount of $\mathrm{Pb}$ (II) on adsorbents $(\mathrm{mg} / \mathrm{g})$ at an equilibrium state, $\mathrm{C}_{\mathrm{e}}$ is the equilibrium concentration of metals $(\mathrm{mg} / \mathrm{g})$, and $\mathrm{K}_{\mathrm{f}}$ and $\mathrm{n}$ are Freundlich constants that are, respectively, related to adsorption capacity and adsorption intensity.

Table 2. Adsorption isotherm parameters calculated from Langmuir and Freundlich models

\begin{tabular}{cccc|ccc}
\hline \multicolumn{3}{c|}{ Langmuir } & \multicolumn{3}{c}{ Freundlich } \\
\hline $\begin{array}{c}\mathrm{K}_{\mathrm{L}} \\
(\mathrm{L} / \mathrm{mol})\end{array}$ & $\mathrm{R}^{2}$ & $\begin{array}{c}\mathrm{E}_{\mathrm{ads}} \\
(\mathrm{kJ} / \mathrm{mol})\end{array}$ & $\begin{array}{c}\mathrm{q}_{\text {maks }}(\mathrm{mg} / \mathrm{g}) \\
\mathrm{K}_{\mathrm{f}} \\
(\mathrm{mol} / \mathrm{g})\end{array}$ & $\mathrm{N}$ & $\mathrm{R}^{2}$ \\
\hline 248182.0664 & 0.9559 & 31.2926 & 7.5141 & 0.1759 & 2.1445 & 0.6996 \\
\hline
\end{tabular}

Table 2 shows that $\mathrm{Pb}^{2+}$ ions adsorption using MIL-100(Fe)-EDTA corresponded to Langmuir model, as the calculated $\mathrm{R}^{2}$ for Langmuir isotherm was higher than that of Freundlich. This model shows that the adsorption process occurred homogenously and generated monolayer 
382 at the surface of MIL-100(Fe)-EDTA, since adsorption could not take place at the already occupied 383 sites and covered surface (Huang et al., 2015). The result also supports the kinetic study and proves 384 that the interaction between $\mathrm{Pb}^{2+}$ ions and MIL-100(Fe)-EDTA is chemisorption.

$386100(\mathrm{Fe})$ followed the Langmuir model, with a maximum adsorption capacity of up to $22.86 \mathrm{mg} / \mathrm{g}$.

387 This suggests that the adsorption process of $\mathrm{Pb}^{2+}$ using both MIL-100(Fe) and MIL-100(Fe)-

388 EDTA occurs at the surface of the material by chemically forming a monolayer with active sites

389 (Kim et al., 2015).

\section{Conclusions}

392 The electrochemical attachment of EDTA to MIL-100(Fe) significantly improved the capability 393 of the material to adsorb $\mathrm{Pb}^{2+}$ ions. The adsorption followed a pseudo-second order kinetic model 394 and Langmuir isotherm that showed that the adsorption occurred via chemisorption. Optimization 395 studies revealed that the maximum adsorption was achieved in a solution with an initial $\mathrm{Pb}^{2+}$ 396 concentration of $5 \mathrm{ppm}$ at pH 3 with a contact time of $12 \mathrm{~h}$. MIL-100(Fe)-EDTA exhibited high 397 stability in the intestinal simulation medium ( $\mathrm{pH}$ 1.2) as well as in the stomach simulation medium 398 ( $\mathrm{pH} \mathrm{6}$ ), indicating that the material has considerable potential for use as a functional $\mathrm{Pb}^{2+}$ 399 detoxification agent in human body. Further in vivo studies related to this study are currently in 400 progress in our group.

\section{Declarations}

405 Not applicable

407 Consent to Participate

408 Not applicable

\section{Consent for Publication}

411 Not applicable 


\section{Availability of Data and Materials}

413 Not applicable

414

\section{Competing Interests}

416 The authors declare that they have no competing interests

\section{$418 \quad$ Funding}

419 This research was funded by Universitas Sebelas Maret via PNBP Research Grant in the scheme

420 Advanced Applied Research (PUT) project number 260/UN27.22/HK.07.00/2021

\section{Authors' Contributions}

423 WWL conceptualized and supervised the research, wrote, revised also analyzed and interpreted

424 the data. $\mathrm{RM}$ performed the synthesis of the material and the examination on $\mathrm{Pb}^{2+}$ adsorption,

425 also wrote the draft. IN supervised the research and interpreted the data. LL wrote and revised

426 the draft.

\section{Acknowledgements}

We would like to acknowledge Universitas Sebelas Maret for a PNBP research grant in the scheme

\section{References}

434 Abednatanzi S, Abbasi A, Masteri-Farahani M (2017) Immobilization of catalytically active polyoxotungstate into ionic liquid-modified MIL-100(Fe): A recyclable catalyst for selective oxidation of benzyl alcohol. Catal Commun. 96:6-10. https://doi.org/10.1016/j.catcom.2017.03.011

Akarmazyan SS, Panagiotopoulou P, Kambolis A, Papadopoulou C, Kondarides DI (2014) Methanol dehydration to dimethylether over $\mathrm{Al}_{2} \mathrm{O}_{3}$ catalysts. Appl Catal B: Environ. 145:136-148. https://doi.org/10.1016/j.apcatb.2012.11.043 
Bezverkhyy I, Weber G, Bellat J (2016) Degradation of fluoride-free MIL-100 (Fe) and MIL-53 $(\mathrm{Fe})$ in water: Effect of temperature and pH. Micropor Mesopor Mater. 219:117-124. https://doi.org/10.1016/j.micromeso.2015.07.037

El-Sayed M, Eshaq G, ElMetwally AE (2016) Adsorption of heavy metals from aqueous solutions by Mg-Al-Zn mingled oxides adsorbent. Water Sci Technol. 74:1644-1657. https://doi.org/10.2166/wst.2016.329

Fang X, Zong B, Mao S (2018) Metal-organic framework-based sensors for environmental contaminant sensing. Nano-Micro Lett. 10:1-19. https://doi.org/10.1007/s40820-0180218-0

Feng L, Cao M, Ma X, Zhu Y, Hu C (2012) Superparamagnetic high-surface-area $\mathrm{Fe}_{3} \mathrm{O}_{4}$ nanoparticles as adsorbents for arsenic removal. J. Hazar. Mater. 217:439-446. https://doi.org/10.1016/j.jhazmat.2012.03.073

Forghani M, Azizi A, Livani MJ, Kafshgari LA (2020) Adsorption of lead(II) and chromium(VI) from aqueous environment onto metal-organic framework MIL-100(Fe): Synthesis kinetics equilibrium and thermodynamics. J. Solid State Chem. 291:121636. https://doi.org/10.1016/j.jssc.2020.121636

Goyal P, Tiwary CS, Misra SK (2021) Ion exchange based approach for rapid and selective Pb(II) removal using iron oxide decorated metal organic framework hybrid. J. Environ Manage 277:111469. https://doi.org/10.1016/j.jenvman.2020.111469

Han L, Qi H, Zhang D, Ye G, Zhou W, Hou C, Sun Y (2017) A facile and green synthesis of MIL100(Fe) with high-yield and its catalytic performance. New J. Chem. 41:13504-13509. https://doi.org/10.1039/C7NJ02975F

Horcajada P, Surblé S, Serre C, Hong DY, Seo YK, Chang JS, Férey G (2007) Synthesis and catalytic properties of MIL-100(Fe) an iron(III) carboxylate with large pores. Chem. Commun. 100:2820-2822. https://doi.org/10.1039/B704325B

Huang G, Wang D, Ma S, Chen J, Jiang L, Wang P (2015) A new low-cost adsorbent: Preparation characterization and adsorption behavior of $\mathrm{Pb}(\mathrm{II})$ and $\mathrm{Cu}(\mathrm{II})$. J. Colloid Interf. Sci. 469 
Huang S, Yang KL, Liu XF, Pan H, Zhang H, Yang S (2017) MIL-100(Fe)-catalyzed efficient conversion of hexoses to lactic acid. RSC Adv. 7:5621-5627. https://doi.org/10.1039/C6RA26469G

Huo SH, Yan XP (2012) Metal-organic framework MIL-100(Fe) for the adsorption of malachite green from aqueous solution. J. Mater. Chem. 22:7449-7455. https://doi.org/10.1039/C2JM16513A

Jin HX, Xu HP, Wang N, Yang LY, Wang YG, Yu D, Ouyang XK (2019). Fabrication of carboxymethylcellulose/metal-organic framework beads for removal of $\mathrm{Pb}$ (II) from Aqueous Solution. Materials 12:942. https://doi.org/10.3390/ma12060942

Kim PJ, You YW, Park H, Chang JS, Bae YS, Lee CH, Suh JK (2015) Separation of SF6 from SF6/N2 mixture using metal-organic framework MIL-100 (Fe) granule. Chem. Eng. J. 262:683-690. https://doi.org/10.1016/j.cej.2014.09.123

Klapiszewski Ł, Bartczak P, Wysokowski M, Jankowska M, Kabat K, Jesionowski T (2015) Silica conjugated with kraft lignin and its use as a novel "green" sorbent for hazardous metal ions removal. Chem. Eng. J. 260:684-693.https://doi.org/10.1016/j.cej.2014.09.054

Lestari WW, Hartono J, Adreane M, Nugrahaningtyas KD, Purnawan C, Rahardjo SB (2016) Electro-synthetic optimization of host material Based on MIL-100 (Fe). Molekul 11:6170. http://dx.doi.org/10.20884/1.jm.2016.11.1.195

Lim TT, Chui PC, Goh KH (2005) Process evaluation for optimization of EDTA use and recovery for heavy metal removal from a contaminated soil. Chemosphere 58:1031-1040. https://doi.org/10.1016/j.chemosphere.2004.09.046

Luo X, Ding L, Luo J (2015) Adsorptive removal of $\mathrm{Pb}$ (II) ions from aqueous samples with aminofunctionalization of metal-organic frameworks MIL-101(Cr). J Chem Eng Data 60:17321743. https://doi.org/10.1021/je501115m

Madadrang CJ, Kim HY, Gao G, Wang N, Zhu J, Feng H, Hou S (2012) Adsorption behavior of EDTA-graphene oxide for $\mathrm{Pb}$ (II) removal. ACS Appl Mater Inter. 4:1186-1193. https://doi.org/10.1021/am201645g

Maiti S, Pramanik A, Manju U, Mahanty S (2015) Reversible lithium storage in manganese 1,3,5Benzenetricarboxylate metal-organic framework with high capacity and rate performance. ACS Appl. Mater. Inter. 7:16357-16363. https://doi.org/10.1021/acsami.5b03414 
Mobasherpour I, Heshajin MS, Kazemzadeh A, Zakeri M (2007) Synthesis of nanocrystalline hydroxyapatite by using precipitation method. J. Alloy Compd. 430:330-333. https://doi.org/10.1016/j.jallcom.2006.05.018

Narayanan A, Dhamodharan R (2015) Super water-absorbing new material from chitosan EDTA and urea. Carbohyd. Polym. 134:337-343. https://doi.org/10.1016/j.carbpol.2015.08.010

Nguyen DTC, Le HTN, Do TS, Pham VT, Tran DL, Ho VTT, Doan VT (2019) Metal-Organic Framework MIL-53(Fe) as an adsorbent for ibuprofen drug removal from aqueous solutions: Response surface modeling and optimization. J. Chem. 2019:1-11. https://doi.org/10.1155/2019/5602957

Obike AI, Igwe JC, Emeruwa CN, Uwakwe KJ (2018) Equilibrium and kinetic studies of Cu (II) $\mathrm{Cd}$ (II) $\mathrm{Pb}$ (II) and $\mathrm{Fe}$ (II) adsorption from aqueous solution using cocoa (Theobroma cacao) pod husk. J. Appl Sci Env Manage. 22:182-190. https://doi.org/10.4314/jasem.v22i2.5

Peng Y, Huang H, Zhang Y, Kang C, Chen S, Song L, Zhong C (2018) A versatile MOF-based trap for heavy metal ion capture and dispersion. Nat. Commun. 9:1-9. https://doi.org/10.1038/s41467-017-02600-2

Rivera JM, Rincón S, Ben Youssef C, Zepeda A (2016) Highly efficient adsorption of aqueous $\mathrm{Pb}$ (II) with mesoporous metal-organic framework-5: An equilibrium and kinetic study. J. Nanomater. 2016:1-9. https://doi.org/10.1155/2016/8095737

Rojas S, Baati T, Njim L, Manchego L, Neffati F, Abdeljelil N, Horcajada P (2018) Metal-organic frameworks as efficient oral detoxifying agents. J. Am Chem Soc.140:9581-9586. https://doi.org/10.1021/jacs.8b04435

Saleh TA, Sari A, Tuzen M (2017) Optimization of parameters with experimental design for the adsorption of mercury using polyethylenimine modified-activated carbon. J. Env. Chem. Eng. 5:1079-1088. https://doi.org/10.1016/j.jece.2017.01.032

Seo YK, Yoon JW, Lee JS, Lee UH, Hwang YK, Jun CH, Chang JS (2012) Large scale fluorinefree synthesis of hierarchically porous iron(III) trimesate MIL-100(Fe) with a zeolite MTN topology. Micropor Mesopor

Mater.

157:137-145. https://doi.org/10.1016/j.micromeso.2012.02.027 
Shi J, Hei S, Liu H, Fu Y, Zhang F, Zhong Y, Zhu W (2013) Synthesis of MIL-100(Fe) at low temperature and atmospheric pressure. J. Chem. 2013:1-4. https://doi.org/10.1155/2013/792827

Sun DT, Peng L, Reeder WS, Moosavi SM, Tiana D, Britt DK, Queen WL (2018) Rapid selective heavy metal removal from water by a metal-organic framework/polydopamine composite. ACS Central Sci. 4:349-356. https://doi.org/10.1021/acscentsci.7b00605

Tanzifi M, Hosseini SH, Kiadehi AD, Olazar M, Karimipour K, Rezaiemehr R, Ali I (2017) Artificial neural network optimization for methyl orange adsorption onto polyaniline nanoadsorbent: Kinetic isotherm and thermodynamic studies. J. Mol. Liq. 244:189-200. https://doi.org/10.1016/j.molliq.2017.08.122

Wang B, Lv XL, Feng D, Xie LH, Zhang J, Li M, Zhou HC (2016) Highly stable Zr(IV)-based metal-organic frameworks for the detection and removal of antibiotics and organic explosives in water. J. Am. Chem. Soc. 138:6204-6216. https://doi.org/10.1021/jacs.6b01663

Wu J, Zhou J, Zhang S, Alsaedi A, Hayat T, Li J, Song Y (2019) Efficient removal of metal contaminants by EDTA modified MOF from aqueous solutions. J. Colloid Interf. Sci. 555:403-412. https://doi.org/10.1016/j.jcis.2019.07.108

Yuan B, Wang X, Zhou X, Xiao J, Li Z (2019) Novel room-temperature synthesis of MIL-100(Fe) and its excellent adsorption performances for separation of light hydrocarbons. Chem. Eng. J. 355:679-686. https://doi.org/10.1016/j.cej.2018.08.201

Zhang H, Wen J, Fang Y, Zhang S, Zeng G (2019) Influence of fulvic acid on Pb(II)removal from water using a post-synthetically modified MIL-100(Fe). J. Colloid Interf. Sci. 551:155163. https://doi.org/10.1016/j.jcis.2019.05.016

Zhang K, Dai Z, Zhang W, Gao Q, Dai Y, Xia F, Zhang X (2021) EDTA-based adsorbents for the removal of metal ions in wastewater. Coordin. Chem. Rev. 434:213809. https://doi.org/10.1016/j.ccr.2021.213809

Zhou J, Liu Y, Zhou X, Ren J, Zhong C (2018) Magnetic multi-porous bio-adsorbent modified with amino siloxane for fast removal of $\mathrm{Pb}(\mathrm{II})$ from aqueous solution. Appl. Surf. Sci. 427:976-985. https://doi.org/10.1016/j.apsusc.2017.08.110 
558 Zhu H, Yuan J, Tan X, Zhang W, Fang M, Wang X (2019) Efficient removal of Pb $2^{+}$by Tb559 MOFs: identifying the adsorption mechanism through experimental and theoretical investigations. Env. Sci.: Nano. 6:261-272. https://doi.org/10.1039/C8EN01066H 


\section{Supplementary Files}

This is a list of supplementary files associated with this preprint. Click to download.

- ElectronicSupportingInformation10082021.docx 